\title{
LOS PROCESOS DE DESCULPABILIZACIÓN EN LA NOVELA FAMILIAR: UN CASO EN MARIO BENEDETTI
}

\section{Jorge CHEN SHAM}

\author{
Universidad de Costa Rica
}

En tanto nociones éticas, la confesión y la culpa nos acercan al proceso de culpabilización y a sus mecanismos, que los sujetos tenemos en el marco de las sociedades modernas para autoengañarnos, porque los actos y la conciencia moral se valoran "de modo congruente con nuestros intereses" (Herra 1993: 11). Tal regla de desculpabilización se puede explicitar del siguiente modo: "actúa de tal manera que la máxima de tu acción sea la de no sentir culpa, no importa lo que hagas" (Herra 1993: 11). Sin embargo, el cinismo y la falta de ética no siempre logran imponerse sobre la responsabilidad moral y, para ello, nos proponemos adentrarnos en un relato de Mario Benedetti, con el fin de que el lector sea crítico ante la tragedia humana que experimenta el niño cuando se enfrenta a su responsabilidad y a su novela familiar. El título del artículo proviene del artículo de Sigmund Freud "la novela familiar del neurótico", en donde él describe el desarrollo del niño en la primera infancia ante el proceso de concientización experimentado cuando descubre otra realidad (autoridad) distinta a la de sus padres. El niño por su desarrollo intelectual empieza a conocer las peculiaridades de los padres en la comparación con otros adultos, como también críticas que retoman experiencias de insatisfacción (Tubert 1997: 65). Por eso, al conocer más a sus progenitores, el niño entra en dudas, los compara y emerge en él una actitud crítica.

Esta actitud crítica conduce al distanciamiento y al sentimiento de sentirse menospreciado. Además, cuando la sexualidad emerge en el niño (pre-pubertad), surge una hostilidad muy clara hacia el padre del mismo sexo (agresión) y una intensidad curiosidad hacia la madre. De manera que el gran tema planteado por Freud aquí es el de las relaciones familiares (1973: 1362), vistas desde el punto de vista del desarrollo sexual del niño y de su poder de fantasear y sustraerse a la realidad. Los relatos en los que la mirada del niño se resquebraja por el descubrimiento de que sus padren no son perfectos ponen en escena, parafraseando a Esther Sánchez-Pardo González, el "malestar en la familia", con la posterior decadencia y desintegración familiares (1997: 173). Éste es el caso de "Réquiem con tostadas", perteneciente al cuentario La muerte y otras sorpresas ( $1^{\text {a }}$. edición de 1968) del escritor uruguayo. La conciencia de Eduardo, el protagonista preadolescente justifica, de esta manera, su ingenuidad y su incapacidad para actuar modificando esa realidad que se descubre alienante y degradada; por ello su relato, el de la confesión que escuchamos los lectores-auditores da respuestas en donde se mezclan lo real y lo imaginario, en un afán de "rectificación de la vida real, principalmente con dos objetivos: el erótico y el ambicioso, aunque detrás del segundo se esconde muchas veces el primero" (Tubert 1997: 66). Lo primero que se desmorona es ese retrato de "album de familia", en el que el niño mira distanciado que él ha participado en la incomunicación, la falsedad que arrastra a su familia (Liano 1983: 203). 
Ahora bien, desde el punto de la vista de la novela familiar en el que este "album de familia" se desmorona, la conducta de Eduardo está marcada por una intensa curiosidad por la madre y el descubrimiento de que su madre era infiel al padre con su interlocutor: Sí, me llamo Eduardo. Usted me lo pregunta para entrar de algún modo en conversación, y eso puedo entenderlo. Pero usted hace mucho que me conoce, aunque de lejos. Como yo lo conozco a usted. Desde la época en que empezó a encontrarse con mi madre en el café de Larrañaga y Rivera, o en éste mismo. (17)

La respuesta de Eduardo da inicio el relato y se supone que responde a una de esas preguntas que tradicionalmente se utilizan para entrar en diálogo o conversación. Eduardo responde directamente y va al grano como si adivinara las intenciones de su interlocutor. "Réquiem con tostadas" se transforma en una conmovedora y trágica confesión en la que su protagonista desea no solo reivindicar a su madre contando la verdad de su historia, sino también conocer las razones por las cuales su madre se vio en la necesidad de buscar cariño y afecto en un hombre extraño. Desde un principio, la madre aparece como una adúltera. Para explicar esto, Eduardo debe justificar lo que, desde las convenciones sociales, se trata de una transgresión a la normas del decoro y de la decencia. El cuadro de una existencia infeliz, de maltrato físico y vejámenes, surge para moldear la figura del esposo y padre machista, violento y borracho, que se desquita con su familia. El padre de Eduardo es el típico agresor, el cual produce miedo y respeto a la vez ${ }^{1}$. Aquí se develan los sentimientos hostiles hacia el padre del mismo sexo, porque Eduardo le achaca a éste la falta de afecto y de amor que llevó a su madre a buscar a otro hombre: Usted apareció hace un año y medio, pero el viejo se emborrachaba desde hace mucho más, y no bien agarró ese vicio nos empezó a pegar a los tres (17-8). Usted conoció a mamá cuando ella ya había aguantado y sufrido mucho $[\ldots]$ (18).

En este cuadro de violencia doméstica y de maltrato familiar, Eduardo hace hincapié en la aparición del amante de la madre, como un salvavidas que hace posible que ella salga del infierno de un matrimonio infeliz y de un marido victimario. Pero lo que más nos interesa ahora es la actitud crítica que establece Eduardo, como si no estuviera satisfecho del mundo que le ha tocado vivir, a la hora de hacer el recuento de su novela familiar. Porque al comenzar la diégesis con la caracterización de una infancia feliz pero con pobreza, "Réquiem con tostadas" insiste en la separación entre el mundo nostálgico de la niñez, en donde la tranquilidad y la armonía dominan las relaciones familiares, y el advenimiento de un nuevo periodo en la vida de familia. El proceso de degradación comienza con un abominable suceso que marca el descenso a los infiernos, "la porquería" (19) que un primo de la madre hizo y que trajo, todo parece indicarlo así, la pérdida de la estabilidad emocional del padre; ${ }^{2}$ desde ese momento, éste empieza a emborracharse y a agredir violentamente a su familia. Con ello, Eduardo descubre una realidad distinta y nueva sobre sus progenitores: un padre violento y una madre que, carente de afecto, busca compañía y amistad en un

\footnotetext{
${ }^{1}$ He aquí una gran constante en muchos cuentos de Benedetti, en donde la figura paternal se degradada constantemente y puede ser interpretado como negación de la Ley y rebelión contra la autoridad; éste es el caso de la novela familiar del neurótico.

${ }^{2} \mathrm{Al}$ respecto agrega el texto: "No supe nunca qué clase de porquería le hizo, pero la verdad era que papá, cada vez que se emborrachaba, se lo reprochaba como si ella fuese la única culpable. Antes de la porquería, nosotros viviamos muy bien. No en cuanto a plata [...]. Hubo muchos días en que pasamos hambre (si viera qué feo es pasar hambre), pero en esa época por lo menos había paz" (18-9).
} 
hombre que se convertirá en su amante. En el caso del padre, nos encontramos con la pérdida de la figura masculina fuerte y protectora; en el caso de la madre, nos enfrentamos a la justificación de su conducta transgresora e ilícita a los ojos de las normas sociales, pero que Eduardo aprueba con satisfacción. Freud habla de la intensa curiosidad sexual que el hijo siente por la madre y de las fantasías que el hijo imagina sobre su infidelidad (1973: 1361-2), como una forma de mostrar un oscuro e implícito sentimiento de agresión en el que se imagina, tal vez, como su sustituto. En el caso de "Réquiem con tostadas", existe una fascinación de Eduardo por su madre, al punto de que descubre en su rostro una transformación. Por eso la sigue y la espía, y cuando nos confiesa que más bien se alegró de que su madre tuviera un amante, comprendemos, más allá del sentimiento de solidaridad afectiva, que con ello se realiza el abandono y la separación del padre castrador y se le encuentra un sustituo posible. Eduardo reivindica el derecho de su madre a la felicidad que el matrimonio le negó: Fue entonces que los vi. A usted y a ella. Yo también me quedé contento. La gente puede pensar que soy un desalmado, y quizá no esté bien eso de haberme alegrado porque mi madre engañaba a mi padre. Puede pensarlo. Por eso nunca lo digo. Con usted es distinto. Usted la quería. Y eso para mí fue algo así como una suerte. Porque ella se merecía que la quisieran (21).

Eduardo nos confiesa que los siguió muchas veces, ¿con qué finalidad? Se trata de una forma de voyeurismo en el hijo que desea ver cómo a su madre la tratan con ternura y cariño, es decir, quiere verla feliz y realizada sexual y emocionalmente en una relación de pareja, a la que él no puede acceder en cuanto hijo. No nos extrañe si nuevamente asociamos esta necesidad de espiar a su madre con la actitud fantaseadora del niño, sólo que aquí la realidad cotidiana es rectificada. Los deseos del preadolescente son varios: a) que su madre encuentre compañero; b) que el mundo de violencia y de carencia en el que ellos viven pueda ser modificado con la aparición del amante, es el elemento exterior que puede revertir la situación del núcleo familiar; c) que, al usurpar los legítimos derechos del marido victimario,.Eduardo encuentre quién se oponga a la figura paterna y la sustituya.

Sin embargo, en una de las tantas veces que Eduardo siguió a los amantes, su padre hace lo mismo $\mathrm{y}$, ante el engaño descubierto, actúa como macho que sanciona su honra con el castigo de quien ha infringido el código del matrimonio, el padre mata en una borrachera a su esposa. Hasta aquí "Réquiem con tostadas" es un ejemplo de la violencia familiar que destruye un hogar; pero, ¿cómo interpretar el final del relato, cuando nos enteramos de que, ante la oportunidad de conversar con el amante de su madre, Eduardo le cuenta, a manera de descargo de su conciencia, la historia que escuchamos en cuanto auditores? Veamos sus palabras: Porque mamá era buena. Usted debe saberlo tan bien como yo. Por eso, hace un rato, cuando usted se me acercó y me invitó a tomar un capuchino con tostadas, aquí en el mismo café donde se citaba con ella, yo sentí que tenía que contarle todo esto (22, el subrayado es nuestro).

No queda claro por qué Eduardo se encuentra ahí, como si esperara que el amante de su madre lo abordara en el café que les servía de punto de reunión. ¿Se sentirá culpable de la muerte de su madre? Todo indica que sí, ya que por su descuido, su padre los ha seguido y ha dado con la pareja. Esta experiencia lo ha afectado significativamente e importa más la manera como dice las cosas que lo que dice explícita- 
mente. Conforme avanza el relato, el lector descubre ciertos hechos que debe relacionar para encontrar la verdad de lo que está en juego y se oculta porque duele y no quiere asumir la responsabilidad. Por ejemplo, Eduardo nos revela que él es un hijo nacido fuera del matrimonio y que existió oposición de las dos familias contra el matrimonio de sus padres: [...] pero cuando papá y mamá se casaron, ellas [las abuelas] se habian opuesto a ese matrimonio (ahora pienso que a lo mejor tenian razón) y cortaron las relaciones con nosotros. Digo nosotros, porque papá y mamá se casaron cuando yo ya tenía seis meses (20).

Resultado: es un hijo no deseado y, desde este punto de vista, el matrimonio de sus padres fue una imposición social, fue forzado para arreglar la honra y el pecado de unas relaciones prematrimoniales. Este hecho es capital para comprender las difíciles relaciones conyugales entre sus padres, lo cual comprueba la exactitud de las siguientes palabras de Eduardo: "Yo creo que ellos nunca se quisieron demasiado. Eran muy distintos. Aun antes de la porquería, cuando papá todavía no tomaba, ya era un tipo bastante alunado" (19). La "porquería", como Eduardo la llama, únicamente viene a agravar la situación y desencadena lo inevitable. Por lo tanto, la vivencia de la culpa, según la denomina Castilla del Pino (1981: 56), aflora ocasionándole remordimientos y un malestar que Eduardo no sabe y no puede explicar. Implica, al mismo tiempo, su incapacidad para ordenar, en forma congruente, su "novela familiar" y sacar la verdad que se esconde en ella. Por eso, "Réquiem con tostadas" es un relato con lagunas. Esto lo comprobamos en la prolijidad de la respuesta de Eduardo. Éste no solo no respira sino que también no hace alguna interrupción -tampoco escuchamos la voz del amante-, como si debiera "desembuchar" todo lo que siente y tiene atragantado en su corazón.

La incapacidad para controlar los hilos de la historia va de la mano con las reacciones que experimenta a lo largo de la conversación: la impotencia ante la violencia física y su poca madurez para comprender el lado oculto de las cosas son el síntoma de su estado emocional. El pre-adolescente no puede reconocer su culpa, aquella que sobreviene cuando se reconoce haber faltado a algún precepto o a alguna norma, cuando se admite que se ha actuado en contra de principios codificados social o culturalmente (Buber 1965:127) o se ha actuado provocando daños y perjuicios a terceros. En este sentido, Carlos Castilla del Pino identifica un origen y un carácter sociogénico en la culpa, pero cuya experiencia siempre es individual (1981: 55). Hay una mancha en Eduardo, es el fruto no tanto del amor de sus padres, sino de una imposición social; pero también tenemos otros tres actos que provocan la vivencia de la culpa: a) Eduardo descubre que su madre es adúltera, que tiene relaciones fuera de su matrimonio y no hace nada, más bien se alegra y actúa como cómplice; consecuencia, como permanece callado alienta el adulterio de la madre. b) Dentro de la relación de codependencia entre el agresor y el agredido, Eduardo reconoce su impotencia, no ha hecho nada para impedir el maltrato físico: consecuencia, él es cómplice también. c) Por espiar y seguir a su madre, el padre descubre in fraganti a los enamorados y, en un acto de venganza, mata a golpes a la esposa; consecuencia, Eduardo actúa indirectamente como el cómplice de su padre y, por medio de él, se castiga a la mujer adúltera. Si no tenía intención de poner en evidencia a su madre y todo era un simple accidente, entonces ¿por qué hace la siguiente pregunta como si demandara de la parte del amante la aprobación de su conducta? Al buscar la justificación al acto de su pa- 
dre, intenta también su posible exculpación: Además estoy seguro de que papá no habría hecho lo que hizo si no hubiese estado tan borracho. ¿O usted cree lo contrario? ¿Usted cree que, de todos modos, hubiera matado a mamá esa tarde en que, por seguirme y castigarme a mí, dio finalmente con ustedes dos? No me parece. Fíjese que a usted no le hizo nada. Sólo más tarde, cuando tomó más grapa que de costumbre, fue que arremetió contra mamá (21-22).

Con la narración, Eduardo se libera de su culpa, en un acto que reivindica la imagen de una madre tierna, abnegada, que tuvo la necesidad de encontrar también la felicidad con un hombre que la comprendiera. De ahí el título del cuento de Benedetti; remite a la misa de difuntos y al "Requiem aeternam dona eis, Domine" 3 , en donde se pide por el eterno descanso del muerto con un ritual en donde se rememora al ausente. "Réquiem con tostadas" es el acto de elogio y de reivindicación de la madre y, para eso, Eduardo cuenta la historia de su familia, pues de seguro el amante ignora muchos detalles de su madre: "A lo mejor usted no lo sabía, o sólo sabía una parte, porque mamá era muy callada y sobre todo no le gustaba hablar de sí misma" (22). El objetivo explícito del encuentro sería informarle al amante "todo sobre su madre", para parafrasear la última película de Pedro Almodóvar;4 de esta manera "Réquiem con tostadas" neutraliza la ausencia de la madre y crea la ilusión de cercanía tanto de la persona que ellos rememoran, como de los interlocutores en el circuito de comunicación (Violi 1987: 95). Recordemos que, gracias a la mediación de la madre, el amante y Eduardo se acercan y se conocen. Sin embargo, no olvidemos que Eduardo se "crea" la imagen (¿será su coartada? ) de una "santa" mujer y se transforma en un "agente moral" que sanciona lo bueno y lo malo, para no desarrollar sentimientos de culpa y de vergüenza; más de una vez enfatiza cuánto amó a su madre, e incluso justifica el adulterio por el hecho de que su madre merecía ser feliz: Yo pienso que, en otras condiciones, él [el padre] habría comprendido que mamá necesitaba carino, necesitaba simpatía, y que él en cambio sólo le había dado golpes (22).

De manera que, en "Réquiem con tostadas", nos adentramos en la manera en que un personaje modela, imaginativamente tal vez como observa Freud en la novela familiar, su interpretación de los recuerdos en un momento en el que enfrenta la orfandad, ya que su padre está en prisión y su hermana Mirta, con una de sus abuelas. La desintegración del hogar da como resultado la desubicación psicológica y social de Eduardo, lo cual implicaría una percepción parcial aunque muy personal (Starobinski 1974: 67) en el autoanálisis de la realidad pasada; por ello, señala Mieke Bal que las formas autobiográficas proporcionan, generalmente, una interpretación poco fiable, y a veces engañosa o desequilibrada, del individuo (1985: 97). Eduardo es un pre-adolescente víctima del maltrato y de la violencia en el que los sentimientos de impotencia, los castigos físicos y la agresión psicológica, el posible choque que puede resultar de ver a su madre con otro hombre, la pobreza extrema, el déficit atencional en una palabra, propician un ambiente malsano y favorecen la decepción y frustración ante este desafortunado panorama familiar que asume las espaldas infantiles de Eduardo; es un peso insoportable para cualquiera. Ante sus confusos ojos de preadolescente todo su mundo se ha cuestionado y se ha destruido. La carga emocional del relato llega a su clímax con el llanto final del amante y tiene la función no tanto

\footnotetext{
${ }^{3}$ Se trata del primer verso de cántico inicial de la misa de difuntos, el cual se llama "Requiem"; la traducción más común del versículo es la siguiente: "Señor, dale el descanso eterno".

${ }^{4}$ Película ganadora de numerosos premios entre ellos el Óscar de la Academia Norteamericana en el 2000.
} 
de apiadarse de la difunta como el objetivo de permitir el descargo de la confesión liberadora, al reconocer en forma implícita el amante que la mamá de Eduardo lo amaba de verdad. La catarsis del desenlace es de ambos a la vez, del amante y de Eduardo.

Pero por otro lado, "Réquiem con tostadas" expone el proceso de desculpabilización, el cual se hace eco del "principio socrático" de quien afirma lo siguiente: "actué mal, pero fue por ignorancia, es decir, no he estado al tanto de los motivos y alcances de mi acción" (Herra 1993: 15). En el uso del español rioplatense existen varias frases hechas con el lexema "tostada"; todas guardan un sentido muy próximo al daño o a la mentira: por ejemplo, "Dar o pegar la tostada" tiene el sentido de "[e]jecutar una acción que redunde en perjuicio suyo, o darle un chasco, sacarle dinero con engaño" (Diccionario de la Real Academia 1992:1419); también tenemos"Olerse la tostada" como "[a]divinar o descubrir algo oculto como artimañas, trampas, etc." (Diccionario de la Real Academia 1992: 1419). Consecuencia de lo anterior, el problema que plantea este relato de Mario Benedetti son las trampas de la desculpabilización del individuo y Mario Benedetti nos invita, en un ejercicio de crítica lectorial, a descubrir las ruedas escondidas de la novela familiar que expone el sujeto víctima/ victimario de "Réquiem con tostadas". El abuso de poder y la violencia hacen de Eduardo una víctima cuyos vínculos con el agresor todavía son fuertes. Podríamos justificar que se trata del síndrome del padre agresor y hablar de codependencia; sin embargo, lo que verdaderamente onnubila la conciencia, nos parece, de este pre-adolescente es la culpa no aceptada pero que surge en su discurso. No se trata, de ninguna manera, de un desdoblamiento en su conciencia ni de una búsqueda angustiosa del individuo, sino de la enajenación de la conciencia enfrascada en el autoengaño de los artificios desculpabilizadores del sujeto (Herra 1993: 14-5) gracias a los que Eduardo clama y siente nostalgia por una infancia feliz que ya no podrá recuperar. Ésa es la gran tragedia y la dolorosa historia que nos plantea "Réquiem con tostadas" 5 .

\section{OBRAS CITADAS}

Bal, Mieke. Teoría de la narrativa (una introducción a la narratología). Madrid: Editorial Cátedra., 1985.

Benedetti, Mario. La muerte y otras sorpresas. 18a. edición. México, D.F.: Siglo Veintiuno Editores, 1982.

Buber, Martin. The Knowledge of Man. London: Allen and Unwin. 1965.

Castilla del Pino, Carlos. La culpa. Madrid: Alianza Editorial, 1981.

Diccionario de la Real Academia. 21a. edición. Madrid: Editorial Espasa-Calpe, 1992.

Freud, Sigmund. "La novela familiar del neurótico". Obras completas. Tomo II. Madrid: Biblioteca Nueva, 1973. 1361-3.

\footnotetext{
${ }^{5}$ Agradezco al Servicio Alemán de Intercambio Académico (DAAD) la beca de investigación-docencia que me otorgó durante los meses de enero -febrero de 1999 en la Justus Liebig Universität Giessen. Gracias a ella terminé este artículo sobre Mario Benedetti.
} 
Herra, Rafael Ángel, “Autoengaño y desculpabilización o crítica de la ética global”, Revista de Filosofía de la Universidad de Costa Rica 31. 74, 1993, 10-16.

Liano, Dante, "'Album de familia': la pequeña burguesía en la narrativa de Mario Benedetti", Studi di Letteratura Ispano-americana 13-14, 1983, 199-212.

Sánchez-Pardo González, Esther, "Malestar en la familia: nuevas filiaciones en las narrativas del fin de siglo", Revista de Occidente 199, 1997, 154-73.

Starobinski, Jean, La relación crítica (Psicoanálisis y literatura), Madrid (Taurus Ediciones) 1974.

Tubert, Irène, “La novela familiar”, Revista de Occidente 199, 1997, 63-89.

Violi, Patrizia, "La intimidad de la ausencia: formas de la estructura epistolar", Revista de Occidente 68, 1987, 87-99. 